\title{
Similar physical characteristics but distinguishable sn-2 palmitic acid content and reduced solid fat content of chemically interesterified palm olein compared with native palm olein by dry fractionation: a lab-scale study
}

\begin{abstract}
The presence of solid fat content (SFC) of vegetable fats at human body temperature $\left(37^{\circ} \mathrm{C}\right)$ has been linked to altered fat digestibility and metabolism. In this study, the possibility of reducing the SFC in chemically interesterified palm olein (CIEPO) while maintaining physical properties similar to native palm olein was explored by dry fractionation. Crystallization at $37^{\circ} \mathrm{C}$ for $155 \mathrm{~min}$ produced a CIEPO olein fraction with total fatty acid composition (FAC) broadly resembling that of native palm olein while the high proportion of $s n-2$ palmitic acid content was maintained at $39.1 \%$. The CIEPO olein fraction has a reduced SFC at $37^{\circ} \mathrm{C}$ from 8.6 to $4.2 \%$, overall decreased SFC, slip melting point (SMP) at $33^{\circ} \mathrm{C}$, a reduced palmitoyl-palmitoyl-palmitoyl (PPP) from 6.0 to $3.7 \mathrm{~mol} \%$ and lower heating peaks in thermal profile compared with the untreated CIEPO. Both CIEPO olein fraction and palm olein have broadly similar total FAC and SMP below $37^{\circ} \mathrm{C}$ but very distinguishable $s n$-2 palmitic acid content. CIEPO olein fraction and native palm olein can be used as effective comparison in human studies because the differences of both fats in PPP content and SFC at $37^{\circ} \mathrm{C}$ were narrowed.
\end{abstract}

Keyword: Chemically interesterified palm olein; Dry fractionation; Solid fat content 